\title{
Metal ion coordination in ' $R$ ' and ' $T$ ' state hybrid hemoglobins as revealed by optical, EPR and sulphhydryl reactivity studies
}

\author{
S RAMASAMY ${ }^{1}$, SWARNALATHA VENKATESHRAO ${ }^{1}, \mathrm{~J}^{\text {M RIFKIND }}{ }^{2}$ and \\ P T MANOHARAN ${ }^{1} *$ \\ ${ }^{1}$ Department of Chemistry and Regional Sophisticated Instrumentation Centre, Indian Institute of \\ Technology - Madras, Chennai 600 036, India \\ ${ }^{2}$ Molecular Dynamics Section, National Institute on Aging, National Institutes of Health, 5600 Nathan \\ Shock Drive, Baltimore, MD 21224, USA \\ e-mail: ptm@rsic.iitm.ernet.in
}

\begin{abstract}
The sulphhydryl environment in various mixed-metal hybrid hemoglobins, viz. $\alpha_{2}(\mathrm{Cu})-$ $\beta_{2}(\mathrm{FeCO}), \alpha_{2}(\mathrm{FeCO})-\beta_{2}(\mathrm{Cu}), \alpha_{2}(\mathrm{Cu})-\beta_{2}(\mathrm{Ni}), \alpha_{2}(\mathrm{Ni})-\beta_{2}(\mathrm{Cu})$, was studied by reacting them with the sulphhydryl reagent, 4,4'-dithiodipyridine (4-PDS). The reactivity was compared with that of $\mathrm{HbCO}, \mathrm{NiHb}$ and $\mathrm{CuHb}$. It is found that there exists a correlation between conformational change and metal ion environment, not only at the extreme $\mathrm{R}$ and $\mathrm{T}$ states but also the intermediate conformations. EPR examinations of these hybrids show that both in $R$ state-[Cu(II)-Fe(II)] and $T$ state-[Cu(II)-Ni(II)] hybrids at neutral $\mathrm{pH}$ and in the absence of IHP, CuPPIX, irrespective of the subunit in which it is present, has a mixed-metal ion environment: Species 1, a five-coordinated $\mathrm{Cu}^{2+}$ complex with strong proximal histidine bond and species 2 , a four-coordinated complex without any covalent linkage with Nع F8-histidine.
\end{abstract}

Keywords. Hybrid hemoglobin; -SH reactivity study; EPR; subunit heterogeneity.

\section{Introduction}

Hemoglobin $(\mathrm{Hb})$ is one of the most representatives of allosteric proteins. The oxygenation process involves 10 partially ligated species including the extreme states - the deoxy $\mathrm{Hb}(\mathrm{T})$ and oxy $\mathrm{Hb}(\mathrm{R})^{1}$. Since oxygen moves from one site to other with great lability, the isolation and study of each partially oxygenated tetramer has not been possible and, for the same reason, the mechanism of cooperative oxygenation is not fully understood. A complete understanding of cooperative behaviour of $\mathrm{Hb}$ requires clear knowledge of the tertiary and quaternary structures of the partially ligated species. Different kinds of hybrid $\mathrm{Hbs}$, for example, valency hybrid $\mathrm{Hb}^{2}$, mixed-metal hybrid $\mathrm{Hb}^{3}$, intersubunit cross-linked hybrid $\mathrm{Hbs},{ }^{4,5}$ which were regarded as models for the intermediate species, have been investigated so far to gain information about the structural aspects of the intermediates. Among these hybrid Hbs, mixed-metal hybrids having an oxy/carbon monoxy/deoxygenated iron (II) porphyrin in either the $\alpha$ (or) $\beta$-subunit, with the

Dedicated to the memory of the late Professor Bhaskar G Maiya *For correspondence

Abbreviations: DTT - dithiothrietol; EPR - electron paramagnetic resonance; $\mathrm{Hb}$ - hemoglobin; 4-PDS - 4,4'-dithiodipyridine other subunit having a heterometallated porphyrin in +2 oxidation state can be regarded as good models for testing the properties of intermediates. A variety of mixed-metal hybrid $\mathrm{Hbs}$ have been studied so far, which include $\mathrm{Co}(\mathrm{II})-\mathrm{Fe}(\mathrm{II}), \mathrm{Ni}(\mathrm{II})-\mathrm{Fe}(\mathrm{II}), \mathrm{Zn}(\mathrm{II})-$ $\mathrm{Fe}(\mathrm{II}), \mathrm{Mn}$ (II)-Fe(II), $\mathrm{Cu}$ (II)-Fe(II) hybrid Hbs.

Perutz proposed that the equilibrium between the two quaternary structures depends on the distance between $\mathrm{N} \varepsilon$ (His-F8) and the plane of the porphyrin. ${ }^{6}$ The $\mathrm{T}$ structure is more stable when both the iron atom and the proximal His-F8 are displaced from the porphyrin plane. The stronger bonds between the subunits in the $\mathrm{T}$ structure might pull the proximal His-F8 away from the porphyrin plane and thus stretch the $\mathrm{Fe}-\mathrm{N} \varepsilon$ (His-F8) bond. It was concluded by Perutz ${ }^{6}$ that the high spin of the ferrous atom and the associated increase in the bond lengths are the principal causes for the low oxygen affinity of the deoxy quaternary structure. The stabilization of the $\mathrm{T}$ structure due to an increase in the $\mathrm{Fe}-\mathrm{N} \varepsilon$ (His-F8) bond distance was a major effect observed only in the $\alpha$-subunits; whereas such stabilization in the $\beta$ subunit was very small. This difference between the two subunits, the so-called subunit heterogeneity or subunit inequivalence, was first identified by Perutz and co-workers from a variety of measurements on 
normal, modified and abnormal Hbs. ${ }^{6-8}$ In situations like low $\mathrm{pH}(\mathrm{pH} \approx 6.5)$ or in the presence of inositolhexaphosphate (IHP), the globin exerts a much larger strain on the $\mathrm{Fe}(\mathrm{II})-\mathrm{N} \varepsilon$ (His-F8) bond in the $\alpha$ subunit than in the $\beta$-subunit and as a result there is a rupture of this bond in the $\alpha$-subunit. A variety of studies which were done in mixed-metal hybrid Hbs and also in other hybrids, viz., EPR, ${ }^{3} \mathrm{NMR},{ }^{9}$ transient $\operatorname{Raman}^{10}$ and oxygen binding studies on $\mathrm{Co}(\mathrm{II})-\mathrm{Fe}(\mathrm{II})$ hybrid Hbs. ${ }^{10}$ Optical, oxygen binding and NMR studies on $\mathrm{Ni}(\mathrm{II})-\mathrm{Fe}(\mathrm{II})$ hybrid $\mathrm{Hbs},{ }^{11,12}$ NMR on $\mathrm{Ru}(\mathrm{II})-\mathrm{Fe}(\mathrm{II}),{ }^{13}$ resonance Raman studies on valency hybrid $\mathrm{Hbs},{ }^{14}$ EPR studies on nitrosyl $\mathrm{Hb}^{15}$ confimed the presence of subunit heterogeneity. All these studies were done with the $\mathrm{Fe}-\mathrm{N} \varepsilon$ (HisF8) bond distance as the major consideration, since the existence of this bond plays a definite role in stabilizing the $\mathrm{R}$ structure. The results from all these studies were that at $\mathrm{pH} 7 \cdot 4, \mathrm{M}^{2+}$ in the $\alpha$-subunit is exclusively 4-coordinate without any covalent linkage with $\mathrm{N} \varepsilon$ (His-F8), whereas that in $\beta$-subunit it is exclusively 5-coordinate with an $\mathrm{M}^{2+}-\mathrm{N} \varepsilon$ (His-F8) bond. Mixed-metal ion coordination, namely 4- and 5-coordination in copper and nickel-reconstituted Hbs were confirmed by employing electron paramagnetic resonance ${ }^{16,17}$ and resonance $\operatorname{Raman}^{18}$ techniques respectively. Identification of the presence of two different metal ion environments in $\mathrm{CuHb}$ was later extended to the mixed-metal hybrid, $[\mathrm{Cu}(\mathrm{II})-\mathrm{Fe}(\mathrm{II})]^{19}$, and based on their X-band EPR measurements, it was concluded that the 5- and 4coordination complexes in $\mathrm{CuHb}$ are localized in $\beta$ and $\alpha$-subunits respectively.

Now an important question that rages is whether the presence of two different metal ion environments is due to subunit heterogeneity or due to their simultaneous presence in both $\alpha$ - and $\beta$-subunits. In other words, whether an increase in bond distance or cleavage of the $\mathrm{M}^{2+}-\mathrm{N} \varepsilon$ (His-F8) bond which leads to stabilization of the $\mathrm{T}$ structure is achieved in the $\alpha$ subunit alone or also in the $\beta$-subunit. Explicitly, whether the two different metal ion coordinations, 4 - and 5-, are localized in $\alpha$ and $\beta$-subunits respectively, or are present in both subunits in different proportions.

This paper tries to find a suitable answer by employing Q-band EPR spectroscopy for several $\mathrm{Cu}$ containing hybrid Hbs both in $\mathrm{R}$ as well as in $\mathrm{T}$ state conformations. We have prepared $\mathrm{Cu}(\mathrm{II})-\mathrm{Fe}(\mathrm{II})$ and $\mathrm{Cu}(\mathrm{II})-\mathrm{Ni}(\mathrm{II})$ mixed-metal hybrid hemoglobins in which heme in either $\alpha$ (or) $\beta$-subunits are substi- tuted with $\mathrm{Cu}$ (II)PPIX or Ni(II)PPIX and studied the sulphhydryl environment by the use of sulphhydryl reagent 4-PDS and heme environment by employing EPR spectroscopy. The advantage of using $\alpha_{2}(\mathrm{Cu})-$ $\beta_{2}(\mathrm{FeCO})$ and $\alpha_{2}(\mathrm{FeCO})-\beta_{2}(\mathrm{Cu})$ hybrid $\mathrm{Hbs}$ is that one can obtain half-liganded $\mathrm{Hb}$ with all porphyrin metals in +2 valence state and the metal ion in the $\alpha$ and the $\beta$-subunits can be looked into separately by means of EPR spectroscopy; whereas the other set of hybrid $\mathrm{Hbs} \alpha_{2}(\mathrm{Cu})-\beta_{2}(\mathrm{Ni})$ and $\alpha_{2}(\mathrm{Ni})-\beta_{2}(\mathrm{Cu})$ are representatives of T-state conformations. Earlier Xband EPR investigation on $\alpha_{2}(\mathrm{Cu})-\beta_{2}(\mathrm{FeCO})$ and $\alpha_{2}(\mathrm{FeCO})-\beta_{2}(\mathrm{Cu})$ hybrid $\mathrm{Hbs}^{19}$ revealed the existence of subunit heterogeneity; but these results should be carefully analysed because in X-band studies, the parallel and the perpendicular features merge, making the analysis complex. So we have attempted to separate out the parallel and the perpendicular features by carrying out the EPR measurements at higher frequency to remove possible uncertainties.

\section{Experimental section}

\subsection{Preparation of hybrid $\mathrm{Hbs}$}

Nickel (II) protoporphyrin IX (NiPPIX) and copper (II) protoporphyrin IX (CuPPIX) were synthesized according to the methods of Shibayama et al. ${ }^{19,20}$ The preparation of $\mathrm{Cu}(\mathrm{II})-\mathrm{Fe}(\mathrm{II})$ hybrid Hbs were achieved by a slight modification of the reported procedure. ${ }^{19} \mathrm{HbA}_{0}$ was prepared in carbonmonoxy form as described by Kilmartin et al. ${ }^{21}$ Separation of $\alpha$ and $\beta$ chains from $\mathrm{HbA}_{0}$ was followed by the procedure of Geraci et al. ${ }^{22}$ Heme-globin separation was carried out by following Rossi-Farelli's acid acetone method. ${ }^{23}$ Preparation of CuPPIX or NiPPIX reconstituted chains were done as reported by Shibayama et al. ${ }^{19,20}$ Metal reconstituted chains in borate buffer were brought to $20 \mathrm{mM}$ Tris- $\mathrm{HCl}$ buffer $\mathrm{pH}$ 8.2. $\beta$-chain was treated with $32 \mathrm{mM}$ DLdithiothreitol (DTT). A complete carbonmonoxy atmosphere was maintained for Fe-containing chains. Metallated $\alpha$ - and $\beta$-chains were mixed in the ratio $1: 1.2$ at $0^{\circ} \mathrm{C}$ and stirred for $2 \mathrm{~h}$. The hybrid thus formed was passed through Sephadex G25 (Fine) in $20 \mathrm{mM}$ Tris- $\mathrm{HCl}$ buffer $\mathrm{pH} 7.2$ and then through DE23 Cellulose (Whatmann) and CM23 Cellulose (Whatmann), both in $20 \mathrm{mM}$ Tris- $\mathrm{HCl}$ buffer $\mathrm{pH}$ 7.2. The sample collected sample concentrated by ultrafiltration and stored in liquid nitrogen. 


\section{$2.2 U V-V i s$ measurements}

Visible spectra were obtained using a double beam Varian Cary 05E spectrophotometer interfaced with an IBM Pentium computer. Spectra were run in the $250-650 \mathrm{~nm}$ regions. All UV-Vis spectral studies were carried out at ambient temperature $\left(\sim 23^{\circ} \mathrm{C}\right)$ with $100 \mu \mathrm{M}$ hybrid $\mathrm{Hb}$ solutions in $20 \mu \mathrm{M}$ Tris$\mathrm{HCl}$ buffer $\mathrm{pH} 7 \cdot 2$.

\section{$2.3-$ SH reactivity study}

The reactivity of free $-\mathrm{SH}$ groups with $4,4^{\prime}$-dithiodipyridine (4-PDS) was monitored spectrophotometrically at $324 \mathrm{~nm}$ as the appearance of 4-thiopyridone. ${ }^{24} \mathrm{~A}$ standard solution of 4-PDS was prepared as follows: $50 \mathrm{mg}$ of 4-PDS was transferred to a $50-\mathrm{ml}$ beaker, dissolved in isotonic sodium chloride solution $(0 \cdot 15 \mathrm{M})$ at $60^{\circ} \mathrm{C}$, cooled and made up to $50 \mathrm{ml}$. Exactly $2.5 \mathrm{ml}$ of the hybrid solution $(7 \mu \mathrm{M}$, tetramer) in $20 \mathrm{mM}$ Tris- $\mathrm{HCl}$ buffer 7.2 was placed in a quartz cuvette. $500 \mu \mathrm{l}$ of 4-PDS $(4.5 \mathrm{mM})$ was added to the $\mathrm{Hb}$ solution and mixed thoroughly, and the reaction was monitored by measuring the increase in absorbance at $324 \mathrm{~nm}$. The dead time of the reaction was $2 \mathrm{~s}$.

\subsection{EPR measurements}

EPR measurements were carried out on a Varian E$112 \mathrm{EPR}$ spectrometer operating with $100 \mathrm{kHz}$ field modulation and phase-sensitive detection to obtain the first derivative signal. For X-band work, a multipurpose Varian $\mathrm{TE}_{102}$ rectangular cavity was employed. All measurements were performed at $77 \mathrm{~K}$ by placing the samples in a cylindrical liquid nitrogen quartz dewar. The Q-band measurements were done on a Variable temperature set up at $100 \mathrm{~K}$ by flowing nitrogen gas through liquid nitrogen using a transfer dewar. A modulation amplitude of $5 \mathrm{G}$, with $10 \mathrm{~mW}$ power, time constant of 64 millisecond and scan time of 4 min were used uniformly. DPPH was used as a $g$-marker.

\section{Results}

\subsection{UV-visible spectra of hybrid hemoglobins}

Figure 1 shows the visible spectra of the hybrid Hbs under study. The visible spectra of all hybrid Hbs exhibit split Soret bands, one occurring around
$400 \mathrm{~nm}$ and the other around $420 \mathrm{~nm}$. The shorter wavelength band $(400 \mathrm{~nm})$ is associated with the $\mathrm{M}^{2+}$ PPIX being 4-coordinated, while the longer wavelength band $(420 \mathrm{~nm})$ is associated with a 5-coordinated $\mathrm{M}^{2+} \mathrm{PPIX}$ complex, with the metal ion covalently bonded to the $\mathrm{Ne}$-His (F8). ${ }^{17,25}$ The exact peak positions of the Soret and Q-band (visible) region for these hybrid Hbs are given in table 1 along with those of copper and nickel-reconstituted hemoglobins. The Soret bands of all the tetrameric Hbs under study were deconvoluted for the presence of 4- and 5-coordinated species. Baseline corrections were properly made for all the $\mathrm{Hb}$ samples during deconvolution. The deconvolution gives information on the peak position, peak height, half-width at half maximum and integrated intensity for the two species (table 2). From the table it is clear that the ratio of integrated intensity of the 5- to 4-coordinated species was found to be in the following order (series 1):

$$
\begin{aligned}
& \mathrm{CuHb}<\mathrm{NiHb}<\alpha_{2}(\mathrm{Cu})-\beta_{2}(\mathrm{Ni})<\alpha_{2}(\mathrm{Ni})_{2^{-}} \\
& \beta_{2}(\mathrm{Cu})<\alpha_{2}(\mathrm{Cu})-\beta_{2}(\mathrm{FeCO})<\mathrm{HbCO}< \\
& \alpha_{2}(\mathrm{FeCO}) \beta_{2}(\mathrm{Cu}),
\end{aligned}
$$

with 4-coordination in $\mathrm{CuHb}$ and 5-coordination in $\alpha_{2}(\mathrm{FeCO})-\beta_{2}(\mathrm{Cu})$.

Alkaline Bohr effect exhibited by hybrid Hbs has been studied extensively by the use of various methodologies such as, optical studies, ${ }^{20} \mathrm{EPR},{ }^{3}$ $\mathrm{NMR}^{12}$ and transient Raman. ${ }^{10} \alpha_{2}(\mathrm{Ni})-\beta_{2}(\mathrm{Fe}-\mathrm{CO})$ hybrid hemoglobin exhibits alkaline Bohr effect. The absorption spectra of $\alpha_{2}(\mathrm{Ni})-\beta_{2}(\mathrm{Fe}-\mathrm{CO})$ hybrid $\mathrm{Hb}$ show marked $\mathrm{pH}$ dependence. ${ }^{20}$ The $\mathrm{pH}$-dependent Soret band positions of this hybrid were deconvoluted and it is found that the ratio of 5- to 4coordination increases as the $\mathrm{pH}$ is raised from 6.5 to 8.5 (table 3). When the visible spectra of $\alpha_{2}(\mathrm{Ni})$ $\beta_{2}(\mathrm{Fe}-\mathrm{CO})$ and $\alpha_{2}(\mathrm{Ni})-\beta_{2}\left(\mathrm{Fe}-\mathrm{O}_{2}\right)$ are compared (fig-

Table 1. The Soret and Q-band maxima in reconstituted and hybrid Hbs.

\begin{tabular}{lcc}
\hline $\begin{array}{l}\text { Reconstituted/ } \\
\text { hybrid Hb's }\end{array}$ & Soret band & Q-band \\
\hline $\mathrm{CuHb}$ & 404,417 & 540,575 \\
$\mathrm{NiHb}$ & 399,420 & $526,558,576$ \\
$\alpha_{2}(\mathrm{Cu})-\beta_{2}(\mathrm{Ni})$ & 403,419 & $542,558,571$ \\
$\alpha_{2}(\mathrm{Ni})-\beta_{2}(\mathrm{Cu})$ & 401,419 & $544,558,577$ \\
$\alpha_{2}(\mathrm{Ni})-\beta_{2}(\mathrm{FeCO})$ & 400,420 & $541,558,575$ \\
$\alpha_{2}(\mathrm{Cu})-\beta_{2}(\mathrm{FeCO})$ & 405,419 & 541,574 \\
$\alpha_{2}(\mathrm{FeCO})-\beta_{2}(\mathrm{Cu})$ & 397,419 & 543,575 \\
\hline
\end{tabular}

All band positions are in nanometres 

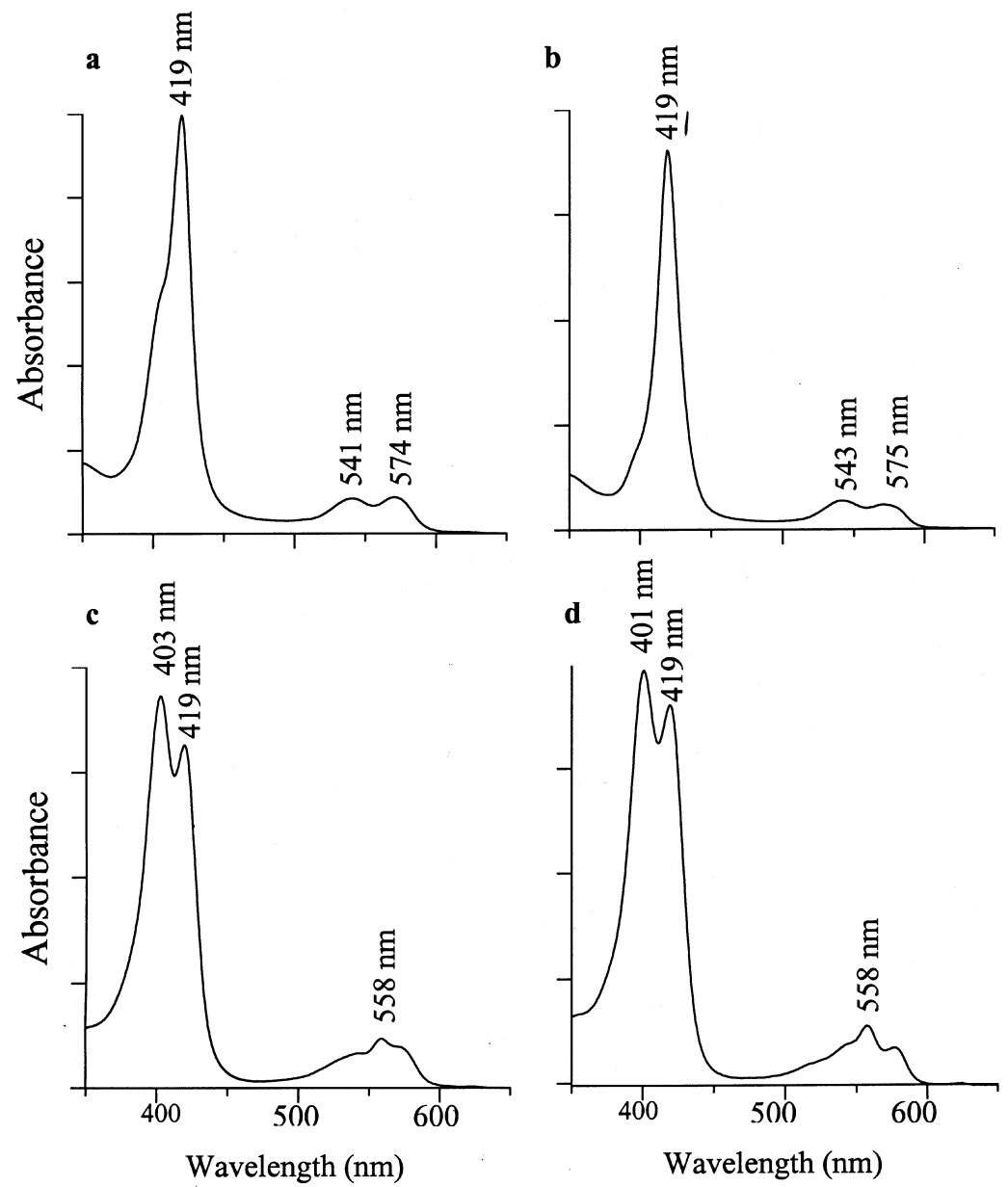

Figure 1. Visible spectra of hybrid Hbs showing the Soret as well as the Q-band regions. (a) $\alpha_{2}(\mathrm{Cu})-\beta_{2}(\mathrm{FeCO})$, (b) $\alpha_{2}(\mathrm{FeCO})-\beta_{2}(\mathrm{Cu}),(\mathbf{c})$ $\alpha_{2}(\mathrm{Cu})-\beta_{2}(\mathrm{Ni}),(\mathbf{d}) \alpha_{2}(\mathrm{Ni})-\beta_{2}(\mathrm{Cu})$.

Table 2. Soret band deconvolution results of reconstituted and hybrid Hbs.

\begin{tabular}{|c|c|c|c|c|c|}
\hline Hb sample & $\begin{array}{l}\text { Peak centre } \\
\left(\mathrm{cm}^{-1}\right)\end{array}$ & $\begin{array}{l}\text { Half width } \\
\quad\left(\mathrm{cm}^{-1}\right)\end{array}$ & $\begin{array}{l}\text { Peak } \\
\text { height }\end{array}$ & $\begin{array}{c}\text { Integrated } \\
\text { intensity }\end{array}$ & $\begin{array}{c}\text { Ratio of area } \\
\text { of 5-coord. to } \\
\text { 4-coord. }\end{array}$ \\
\hline \multirow[t]{2}{*}{$\mathrm{CuHb}$} & $23646 \cdot 57^{\mathrm{a}}$ & $466 \cdot 96$ & $0 \cdot 149$ & $118 \cdot 78$ & \multirow[t]{2}{*}{$0 \cdot 305$} \\
\hline & $24730 \cdot 34^{\mathrm{b}}$ & $805 \cdot 56$ & $0 \cdot 284$ & $389 \cdot 43$ & \\
\hline \multirow[t]{2}{*}{$\mathrm{NiHb}$} & $23745 \cdot 66^{\mathrm{a}}$ & $537 \cdot 96$ & 0.717 & $655 \cdot 51$ & \multirow[t]{2}{*}{$0 \cdot 59$} \\
\hline & $25077 \cdot 64^{b}$ & $716 \cdot 84$ & $0 \cdot 914$ & $1113 \cdot 76$ & \\
\hline \multirow[t]{2}{*}{$\alpha_{2}(\mathrm{Cu})-\beta_{2}(\mathrm{Ni})$} & $23735 \cdot 31^{\mathrm{a}}$ & $500 \cdot 68$ & 0.439 & $374 \cdot 13$ & \multirow[t]{2}{*}{$0 \cdot 64$} \\
\hline & $24848 \cdot 38^{b}$ & $715 \cdot 61$ & $0 \cdot 478$ & $582 \cdot 02$ & \\
\hline \multirow[t]{2}{*}{$\alpha_{2}(\mathrm{Ni})-\beta_{2}(\mathrm{Cu})$} & $23744 \cdot 38^{\mathrm{a}}$ & $578 \cdot 82$ & $0 \cdot 108$ & $106 \cdot 66$ & \multirow[t]{2}{*}{$0 \cdot 66$} \\
\hline & $24957 \cdot 78^{b}$ & $797 \cdot 92$ & $0 \cdot 119$ & $162 \cdot 16$ & \\
\hline \multirow[t]{2}{*}{$\alpha_{2}(\mathrm{Ni})-\beta_{2}(\mathrm{FeCO})$} & $23780 \cdot 02^{\mathrm{a}}$ & $500 \cdot 99$ & $0 \cdot 0782$ & $66 \cdot 58$ & \multirow[t]{2}{*}{0.9497} \\
\hline & $25026 \cdot 68^{b}$ & $721 \cdot 22$ & 0.0572 & $70 \cdot 10$ & \\
\hline \multirow[t]{2}{*}{$\alpha_{2}(\mathrm{Cu})-\beta_{2}(\mathrm{Fe}-\mathrm{CO})$} & $23762 \cdot 12^{\mathrm{a}}$ & $480 \cdot 91$ & $0 \cdot 370$ & $302 \cdot 98$ & \multirow[t]{2}{*}{$1 \cdot 70$} \\
\hline & $24658 \cdot 14^{\mathrm{b}}$ & $646 \cdot 18$ & $0 \cdot 162$ & $177 \cdot 73$ & \\
\hline \multirow[t]{2}{*}{$\mathrm{FeHb}(\mathrm{CO})$} & $23825 \cdot 56^{\mathrm{a}}$ & 469.99 & $1 \cdot 1513$ & 919.93 & \multirow[t]{2}{*}{$4 \cdot 01$} \\
\hline & $24650 \cdot 04^{b}$ & $739 \cdot 18$ & $0 \cdot 1824$ & $229 \cdot 27$ & \\
\hline \multirow[t]{2}{*}{$\alpha_{2}(\mathrm{Fe}-\mathrm{CO})-\beta_{2}(\mathrm{Cu})$} & $23832 \cdot 1^{\mathrm{a}}$ & $568 \cdot 20$ & $1 \cdot 2271$ & $1185 \cdot 40$ & \multirow[t]{2}{*}{$6 \cdot 30$} \\
\hline & $25010 \cdot 63^{b}$ & $674 \cdot 55$ & $0 \cdot 1640$ & $188 \cdot 15$ & \\
\hline
\end{tabular}

${ }^{\mathrm{a}} 5$-Coordinated species; ${ }^{\mathrm{b}} 4$-coordinated species 
Table 3. Soret band deconvolution results of $\alpha_{2}(\mathrm{Ni})-\beta_{2}(\mathrm{FeCO})$ hybrid $\mathrm{Hb}$ at 3 different pH's and $\alpha_{2}(\mathrm{Ni})-\beta_{2}\left(\mathrm{FeO}_{2}\right)$ hybrid $\mathrm{Hb}$.

\begin{tabular}{|c|c|c|c|c|c|c|}
\hline Hybrid $\mathrm{Hb}$ & $\mathrm{pH}$ & $\begin{array}{l}\text { Peak centre } \\
\quad\left(\mathrm{cm}^{-1}\right)\end{array}$ & $\begin{array}{l}\text { Half width } \\
\left(\mathrm{cm}^{-1}\right)\end{array}$ & $\begin{array}{c}\text { Peak } \\
\text { height }\end{array}$ & $\begin{array}{c}\text { Intensity } \\
\text { integrated }\end{array}$ & $\begin{array}{l}\text { Ratio of area } \\
\text { of 5-coord. } \\
\text { to 4-coord. }\end{array}$ \\
\hline \multirow[t]{6}{*}{$\alpha_{2}(\mathrm{Ni})-\beta_{2}(\mathrm{FeCO})$} & \multirow[t]{2}{*}{$6 \cdot 5$} & $23780 \cdot 02^{\mathrm{a}}$ & $500 \cdot 99$ & 0.0782 & $66 \cdot 58$ & \multirow[t]{2}{*}{0.5686} \\
\hline & & $25026 \cdot 68^{\mathrm{b}}$ & $721 \cdot 22$ & 0.0572 & $70 \cdot 10$ & \\
\hline & \multirow[t]{2}{*}{$7 \cdot 2$} & $23780 \cdot 02^{\mathrm{a}}$ & $500 \cdot 99$ & 0.0782 & $66 \cdot 58$ & \multirow[t]{2}{*}{0.9497} \\
\hline & & $25026 \cdot 68^{\mathrm{b}}$ & $721 \cdot 22$ & 0.0572 & $70 \cdot 10$ & \\
\hline & \multirow[t]{2}{*}{$8 \cdot 5$} & $23770 \cdot 82^{a}$ & $499 \cdot 40$ & 0.9877 & 838.56 & \multirow[t]{2}{*}{1.5189} \\
\hline & & $24976 \cdot 51^{\mathrm{b}}$ & 758.94 & 0.4279 & 552.06 & \\
\hline \multirow{2}{*}{$\alpha_{2}(\mathrm{Ni})-\beta_{2}\left(\mathrm{FeO}_{2}\right)$} & $7 \cdot 2$ & $23838 \cdot 02^{\mathrm{a}}$ & $642 \cdot 33$ & 0.4336 & $473 \cdot 44$ & \multirow[t]{2}{*}{0.6865} \\
\hline & & $25011 \cdot 33^{\mathrm{b}}$ & $758 \cdot 91$ & 0.5345 & 689.59 & \\
\hline
\end{tabular}

a-Coordinated species; ${ }^{\mathrm{b}} 4$-coordinated species

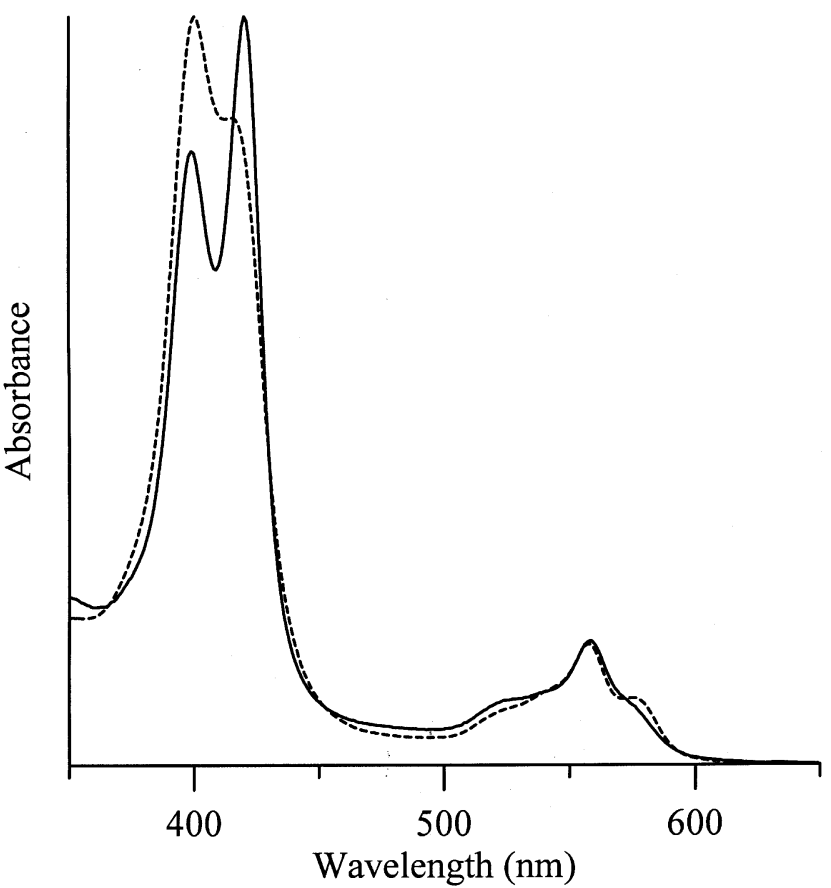

Figure 2. Comparison of the visible spectra of $\alpha_{2}(\mathrm{Ni})$ $\beta_{2}(\mathrm{FeCO})$ (solid line) and $\alpha_{2}(\mathrm{Ni})-\beta_{2}\left(\mathrm{FeO}_{2}\right)$ (dashed line) in $20 \mathrm{mM}$ Tris- $\mathrm{HCl} \mathrm{pH}$ 7.2.

ure 2), by deconvoluting their Soret bands, it is found that the carbonmonoxy derivative has a higher ratio of integrated intensities of 5- to 4-coordination than the oxy derivative (table 3 ).

\subsection{Sulphhydryl reactivity study}

When $-\mathrm{SH}$ reactivity studies were performed for these hybrid and reconstituted Hbs it was realized that there is a one-to-one correspondence between our deconvolution result and the -SH reactivity profile. $\mathrm{CuHb}$, which has the lowest ratio of integrated intensity of 5- to 4-coordinated species, showed the lowest reactivity and the $\alpha_{2}(\mathrm{FeCO})-\beta_{2}(\mathrm{Cu})$ hybrid, the which has maximum ratio, showed the highest reactivity. All the other hybrid Hbs exhibited a reactivity profile in between these two extreme cases (figure 3 ). Since the $-\mathrm{SH}$ reactivity profiles of $\alpha_{2}(\mathrm{Cu})-\beta_{2}(\mathrm{Ni})$ and $\alpha_{2}(\mathrm{Ni})-\beta_{2}(\mathrm{Cu})$ are close to $\mathrm{NiHb}$ (a representative of $\mathrm{T}$-state $\mathrm{Hb}$ ) these two hybrids can be termed T-state hybrids. On the other hand, the $-\mathrm{SH}$ reactivity profiles of $\alpha_{2}(\mathrm{Cu})-\beta_{2}(\mathrm{Fe}-\mathrm{CO})$ and its complimentary hybrid $\alpha_{2}(\mathrm{Fe}-\mathrm{CO})-\beta_{2}(\mathrm{Cu})$ are comparable to that of $\mathrm{HbCO}$, hence these hybrid $\mathrm{Hbs}$ can be termed R-state hybrids.

-SH group reactivity study was conducted on $\alpha_{2}(\mathrm{Ni})-\beta_{2}(\mathrm{Fe}-\mathrm{CO})$ hybrid $\mathrm{Hb}$ at three $\mathrm{pH}$ values, 6.5, 7.2 and 8.5 (figure 4 ) and it was found that the reactivity profile increases as the $\mathrm{pH}$ is raised from 6.5 . Similarly, the sulphhydryl reactivity of $\alpha_{2}(\mathrm{Ni})$ $\beta_{2}\left(\mathrm{Fe}-\mathrm{O}_{2}\right)$ hybrid $\mathrm{Hb}$ was also measured and compared with that of $\alpha_{2}(\mathrm{Ni})-\beta_{2}(\mathrm{Fe}-\mathrm{CO})$ at $\mathrm{pH} 7 \cdot 2$. It was found that the carbonmonoxy derivative showed higher reactivity than the oxy derivative (figure 5).

\subsection{EPR measurements}

The paramagnetic copper(II) centre has been effectively used to decipher the type of coordination found in $\alpha_{2}(\mathrm{Cu})-\beta_{2}(\mathrm{FeCO}), \alpha_{2}(\mathrm{FeCO})-\beta_{2}(\mathrm{Cu})$ (R-state hybrids $), \alpha_{2}(\mathrm{Cu})-\beta_{2}(\mathrm{Ni})$ and $\alpha_{2}(\mathrm{Ni})-\beta_{2}(\mathrm{Cu})$ hybrid $\mathrm{Hbs}$ (T-state hybrids). The X-band EPR spectra of these hybrid Hbs are complex due to two reasons: (i) the parallel and the perpendicular lines merge together making the analysis complex; (ii) the hybrid Hbs 
contained $\mathrm{Cu}(\mathrm{II})$ ion with natural isotopic abundance of ${ }^{63} \mathrm{Cu}$ and ${ }^{65} \mathrm{Cu}$. The first point of complexity was circumvented by recording the EPR at higher frequency, i.e., at Q-band frequency. The second point was taken care of during simulation of the Q-band EPR spectrum by the inclusion of isotopic compensation and their change in magnetic moments.

In the EPR spectra of all these four hybrid Hbs recorded at Q-band fields, the parallel lines completely separated out from the perpendicular features and contain two sets of four lines partially superimposed (figures 6a, b, 7 and 8). This indicates the presence of two different copper ion environments,



Figure 3. Reactivity profile of the sulphhydryl group of normal, reconstituted and hybrid Hbs towards 4-PDS.

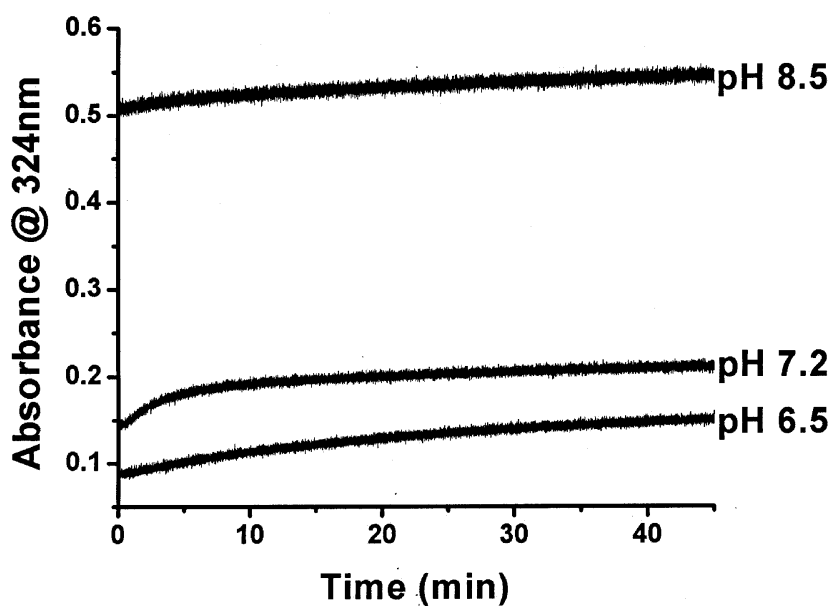

Figure 4. Reactivity profile of the sulphhydryl group of $\alpha_{2}(\mathrm{Ni})-\beta_{2}(\mathrm{FeCO})$ hybrid $\mathrm{Hb}$ at three different $\mathrm{pH}$ values towards 4-PDS. namely, 4-coordinated $\mathrm{M}^{2+} \mathrm{PPIX}$ and 5-coordinated $\mathrm{M}^{2+}$ PPIX for all these hybrid $\mathrm{Hbs}$ with differing intensity ratios. The perpendicular features of these hybrid Hbs having two components, one with distinctly narrowed superhyperfine lines and another with broadened unresolved superhyperfine structure, again indicates that the $\mathrm{Cu}(\mathrm{II})$ ions in both these hybrid Hbs possess of two different metal ion environments.

Though reasonable EPR parameters can be obtained from parallel component, computer simulations were needed to obtain the perpendicular components and the relative amounts of species with reasonable accuracy using the Hamiltonian,

$$
\begin{aligned}
\mathrm{H}= & g_{\|} \beta B_{z} S_{z}+g_{\perp} \beta\left(B_{x} S_{x}+B_{y} S_{y}\right)+A_{\|} S_{z} I_{z}+ \\
& A_{\perp}\left(S_{x} I_{x}+S_{y} I_{y}\right)+Q^{\prime}\left[I_{z}-3 I(I+1)\right]+\Sigma S A_{N} I^{n} .
\end{aligned}
$$

The parameters for the 5-coordinated species 1 and 4-coordinated species 2 were obtained from earlier work of Manoharan and co-workers. ${ }^{17}$ A comparison of the experimental and the simulated spectra of the $\mathrm{R}$-state hybrid $\mathrm{Hbs}$ for the perpendicular regions are given in figures 7 and 8 . In the case of ' $R$ '-state hybrid $\mathrm{Hb}$, the best match between the observed and simulated spectra of $\alpha_{2}(\mathrm{Cu})-\beta_{2}(\mathrm{FeCO})$ hybrid $\mathrm{Hb}$ was obtained when species 1 and 2 were combined in the ratio of $40: 60$; whereas this ratio for $\alpha_{2}(\mathrm{FeCO})-\beta_{2}(\mathrm{Cu})$ hybrid $\mathrm{Hb}$ was $75: 25$. In the case of ' $\mathrm{T}$ '-state hybrid $\mathrm{Hb}$, the best fit for $\alpha_{2}(\mathrm{Cu})-\beta_{2}(\mathrm{Ni})$ was obtained when species 1 and 2 were combined in the percentage ratio of $40: 60$; whereas the same

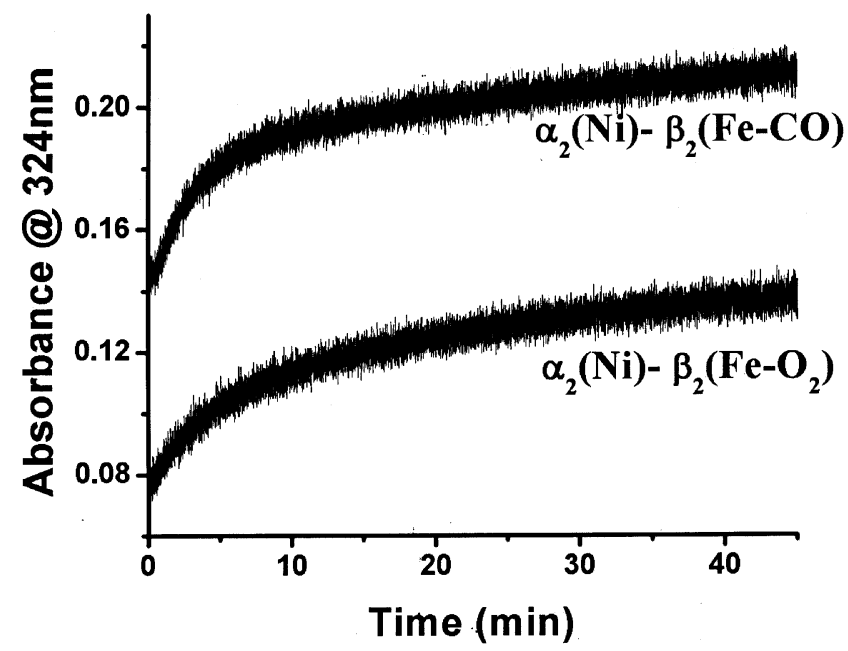

Figure 5. Comparison of the reactivity profiles of the sulphhydryl group of $\alpha_{2}(\mathrm{Ni})-\beta_{2}(\mathrm{FeCO})$ hybrid $\mathrm{Hb}$ and $\alpha_{2}(\mathrm{Ni})-\beta_{2}\left(\mathrm{FeO}_{2}\right)$ towards 4-PDS. 

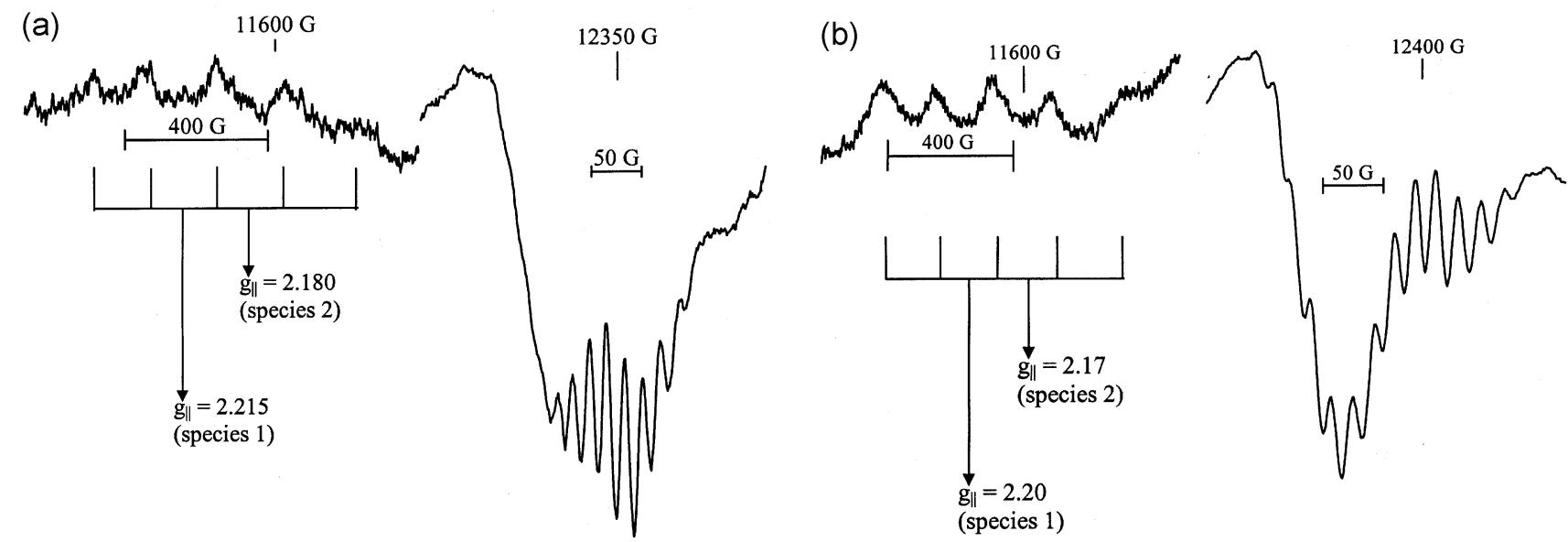

Figure 6. Q-band EPR spectra of hybrid Hbs in $20 \mathrm{mM}$ Tris-HCl buffer $\mathrm{pH} 7.2$ showing the parallel as well as the perpendicular regions recorded at $90 \mathrm{~K}$. (a) $\alpha_{2}(\mathrm{Cu})-\beta_{2}(\mathrm{Ni}),(\mathbf{b}) \alpha_{2}(\mathrm{Ni})-\beta_{2}(\mathrm{Cu})$.

Table 4. Comparison of EPR spectral parameters of $\alpha_{2}(\mathrm{Cu})-\beta_{2}(\mathrm{FeCO}), \alpha_{2}(\mathrm{FeCO})-\beta_{2}(\mathrm{Cu}), \alpha_{2}(\mathrm{Cu})-\beta_{2}(\mathrm{Ni}), \alpha_{2}(\mathrm{Ni})-$ $\beta_{2}(\mathrm{Cu}), \mathrm{CuHb}$ and $\mathrm{Cu}(\mathrm{II})$ porphyrin complexes.

\begin{tabular}{|c|c|c|c|c|c|c|c|}
\hline Reconstituted/hybrid Hb & & $g_{\|}$ & $g_{\perp}$ & $A_{\|}^{*}(\mathrm{Cu})$ & $A_{\perp} *(\mathrm{Cu})$ & $A_{\|}^{*}(N)$ & $A_{\perp} *(N)$ \\
\hline \multirow{2}{*}{$\alpha_{2}(\mathrm{Cu})-\beta_{2}(\mathrm{FeCO})$} & Species $1(40 \%)$ & $2 \cdot 210$ & $2 \cdot 044$ & $178 \cdot 8$ & $11 \cdot 7$ & $14 \cdot 6$ & 14.4 \\
\hline & Species $2(60 \%)$ & $2 \cdot 176$ & $2 \cdot 035$ & $191 \cdot 0$ & $20 \cdot 0$ & $14 \cdot 6$ & 19.1 \\
\hline \multirow[t]{2}{*}{$\alpha_{2}(\mathrm{FeCO})-\beta_{2}(\mathrm{Cu})$} & Species $1(75 \%)$ & $2 \cdot 218$ & $2 \cdot 048$ & $182 \cdot 0$ & $14 \cdot 7$ & $14 \cdot 6$ & 14.4 \\
\hline & Species $2(25 \%)$ & $2 \cdot 179$ & $2 \cdot 040$ & $191 \cdot 0$ & $19 \cdot 1$ & $14 \cdot 6$ & 18.8 \\
\hline \multirow[t]{2}{*}{$\alpha_{2}(\mathrm{Cu})-\beta_{2}(\mathrm{Ni})$} & Species $1(40 \%)$ & $2 \cdot 215$ & $2 \cdot 045$ & $177 \cdot 0$ & $12 \cdot 7$ & $14 \cdot 6$ & 14.3 \\
\hline & Species $2(60 \%)$ & $2 \cdot 180$ & $2 \cdot 040$ & $210 \cdot 0$ & $19 \cdot 8$ & $16 \cdot 6$ & 18.4 \\
\hline \multirow[t]{2}{*}{$\alpha_{2}(\mathrm{Ni})-\beta_{2}(\mathrm{Cu})$} & Species $1(60 \%)$ & $2 \cdot 208$ & $2 \cdot 037$ & $182 \cdot 0$ & $14 \cdot 4$ & $14 \cdot 6$ & 14.4 \\
\hline & Species $2(40 \%)$ & $2 \cdot 17$ & $2 \cdot 027$ & $191 \cdot 0$ & $18 \cdot 1$ & $14 \cdot 6$ & 18.8 \\
\hline \multirow[t]{2}{*}{$\mathrm{CuHb}^{\mathrm{a}}$} & Species $1(50 \%)$ & $2 \cdot 217$ & $2 \cdot 054$ & $179 \cdot 3$ & $11 \cdot 7$ & $16 \cdot 6$ & 14.4 \\
\hline & Species $2(50 \%)$ & $2 \cdot 178$ & $2 \cdot 042$ & $193 \cdot 6$ & $19 \cdot 8$ & $14 \cdot 3$ & 16.5 \\
\hline $\mathrm{CuMb}^{\mathrm{a}}$ (with axial ligand) & & $2 \cdot 214$ & $2 \cdot 045$ & $178 \cdot 5$ & $12 \cdot 0$ & $14 \cdot 6$ & $14 \cdot 4$ \\
\hline $\begin{array}{l}\mathrm{CuTPP} \text { in } \mathrm{CHCl}_{3}{ }^{\mathrm{b}} \\
\text { (no axial ligand) }\end{array}$ & & $2 \cdot 187$ & $2 \cdot 032$ & $209 \cdot 0$ & $31 \cdot 8$ & $14 \cdot 4$ & $15 \cdot 9$ \\
\hline $\begin{array}{l}\text { CuTPP-1-methyl imidazole }{ }^{\mathrm{c}} \\
\text { (strong axial ligand) }\end{array}$ & & $2 \cdot 225$ & $2 \cdot 054$ & $186 \cdot 0$ & $34 \cdot 2$ & $13 \cdot 5$ & $14 \cdot 8$ \\
\hline
\end{tabular}

*A values in $10^{-4} \mathrm{~cm}^{-1}$; ${ }^{a}$ ref. [17]; ${ }^{b}$ ref. [29]; ${ }^{c}$ ref. [28]

for $\alpha_{2}(\mathrm{Ni})-\beta_{2}(\mathrm{Cu})$ hybrid $\mathrm{Hb}$ was $60: 40$. Table 4 gives a compilation of the EPR parameters of these hybrids with species 1 and 2 along with those for pure four- and five-coordinated copper(II) porphyrin systems.

\subsection{IHP induced quaternary structural changes in $\alpha_{2}(\mathrm{Cu})-\beta_{2}(\mathrm{Ni})$ and $\alpha_{2}(\mathrm{Ni})-\beta_{2}(\mathrm{Cu})$ hybrid $\mathrm{Hbs}$}

Earlier studies have shown that addition of IHP induces the rupture of the metal-nitrogen (NE-His F8) bond in the $\alpha$-subunit but not in the $\beta$-subunit. ${ }^{15}$ This inequivalence among the subunits was reflected in our experiments on IHP induced quaternary structural changes in $\alpha_{2}(\mathrm{Cu})-\beta_{2}(\mathrm{Ni})$ and $\alpha_{2}(\mathrm{Ni})-\beta_{2}(\mathrm{Cu})$ hybrid Hbs as observed by Q-band EPR spectroscopy.

The Q-band EPR spectrum of IHP-treated $\alpha_{2}(\mathrm{Cu})$ $\beta_{2}(\mathrm{Ni})$ (data not shown) shows the presence of only 4 parallel lines with $g_{\|}$value of 2.180 and $A_{\|}$value of $210 \times 10^{-4} \mathrm{~cm}^{-1}$ and highly resolved perpendicular lines (this being characteristic of 4-coordinate species) indicating the presence of only a single species, the four-coordinated species of CuPPIX. This is in contrast to the observation of two species before the IHP treatment. The Q-band EPR spectra of the IHP-treated $\alpha_{2}(\mathrm{Ni})-\beta_{2}(\mathrm{Cu})$ hybrid, however, 
still exhibits the mixed-metal ion coordination behaviour and there is very little difference between the $\alpha_{2}(\mathrm{Ni})-\beta_{2}(\mathrm{Cu})$ spectrum with and without IHP (figure 9). This shows that CuPPIX in the $\beta$-subunit is unaffected by the addition of IHP, an observation supporting the subunit heterogeneity.

\section{Discussion}

\subsection{Soret band deconvolution}

A study of this kind can throw light on two different aspects of the metal-reconstituted and hybrid hemoglobins, one dealing with conformational change and another pertaining to the differing metal ion environment in different conformations. The most interesting thing is the connection between these two aspects, which in effect is crucial for determining the presence of subunit heterogeneity or otherwise.

It is known that $\mathrm{HbCO}$ which falls at the right extreme of the 5-4 coordination ratio series (1) is in $\mathrm{R}$ conformation, whereas $\mathrm{CuHb}$ which falls at the left extreme is representative of T-state conformation. ${ }^{17}$ Our deconvolution results also echo the same trend. $\mathrm{CuHb}$, the T-state tetramer, has the lowest ratio of integrated intensity of 5- to 4-coordination where as, $\mathrm{HbCO}$ - the R-state tetramer has a very high ratio. The $\alpha_{2}(\mathrm{Fe}-\mathrm{CO})-\beta_{2}(\mathrm{Cu})$ hybrid which has the highest ratio among all hybrids is at the extreme end of $\mathrm{R}$ -



Figure 7. Comparison of the experimental Q-band EPR spectrum (solid line) of $\alpha_{2}(\mathrm{Cu})-\beta_{2}(\mathrm{Fe}-\mathrm{CO})$ hybrid $\mathrm{Hb}$ and the simulated spectrum (dashed line) due to combination of species 1 and species 2 in the ratio $40: 60$. Only the perpendicular region is shown. state conformation. The rest of the hybrid Hbs which fall in between these two extremes are representative of intermediate R states (R's).

From the deconvoluted data, it is observed that the half width at half maximum of the lower wavelength (4-coordinated) peak is more than that of the higher wavelength (5-coordinated) peak for the entire set of hemoglobins. This observation can be considered proof of the integrity of our deconvolution results because in the 4-coordinated species, the central metal ion in the porphyrin is not covalently linked to the proximal histidine or any other group and so the porphyrin is not rigidly held except for some Van der Waals' contacts between the heme group and the amino acid groups in the peripheral region. So the linewidth associated with the 4-coordinated heme is expected to be greater in view of the loosening of the metal to nitrogen bond leading to its higher motional behaviour. However, the central metal ion of the porphyrin ring in the 5-coordinated species is covalently bonded to the nitrogen atom of the proximal histidine and, hence, the porphyrin ring is arrested from exhibiting any random motion, resulting in smaller line width than that for the 4-coordination situation.

Furthermore, the spectral changes of $\alpha_{2}(\mathrm{Ni})$ $\beta_{2}(\mathrm{Fe}-\mathrm{CO})$ hybrid with $\mathrm{pH}$ variation - alkaline Bohr effect - are attributable to the change of coordination state of NiPPIX in the $\alpha$-subunit; namely 4 -coordinated NiPPIX dominates at $\mathrm{pH} 6.5$ and the contribution of 5-coordination increases on raising the $\mathrm{pH} .{ }^{20}$

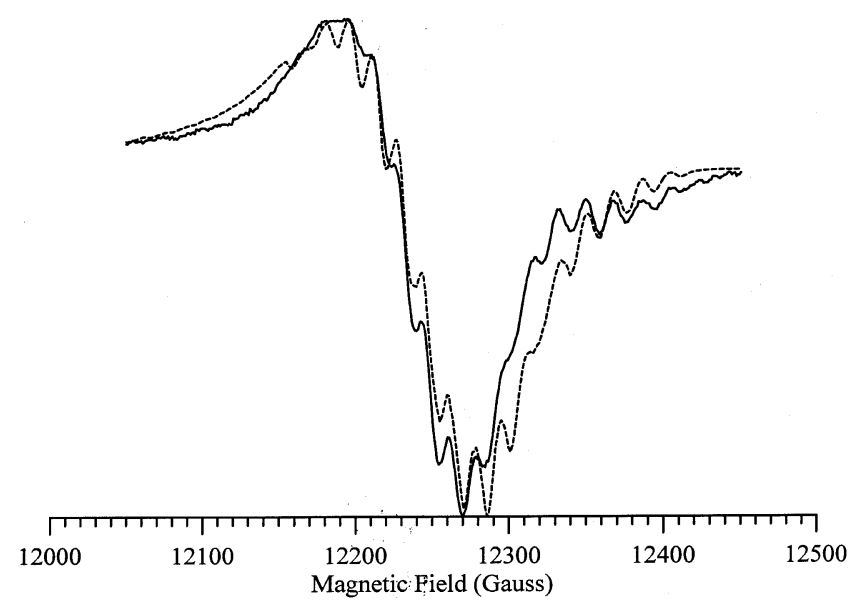

Figure 8. Comparison of the experimental Q-band EPR spectrum (solid line) of $\alpha_{2}(\mathrm{Fe}-\mathrm{CO})-\beta_{2}(\mathrm{Cu})$ hybrid $\mathrm{Hb}$ and the simulated spectrum (dashed line) due to combination of species 1 and species 2 in the ratio $75: 25$. Only the perpendicular region is shown. 



Figure 9. Comparison of the experimental Q-band EPR spectra of $\alpha_{2}(\mathrm{Ni})-\beta_{2}(\mathrm{Cu})$ hybrid Hb presence (solid line) and absence (dotted line) of IHP. (a) Full region; (b) perpendicular region alone.

The markedly differing intensities of 5- and 4coordination (figure 2) in the visible spectra of $\alpha_{2}(\mathrm{Ni})-\beta_{2}(\mathrm{Fe}-\mathrm{CO})$ and $\alpha_{2}(\mathrm{Ni})-\beta_{2}\left(\mathrm{Fe}-\mathrm{O}_{2}\right)$ show that the carbonmonoxy derivative is substantially more $\mathrm{R}$ structured than the oxy derivative (table 3 ). The difference in the visible spectra of $\alpha_{2}(\mathrm{Ni})-\beta_{2}(\mathrm{Fe}-\mathrm{CO})$ and $\alpha_{2}(\mathrm{Ni})-\beta_{2}\left(\mathrm{Fe}-\mathrm{O}_{2}\right)$ hybrid $\mathrm{Hbs}$ can be attributed to the fact that complete oxygenation of $\alpha_{2}(\mathrm{Ni})$ $\beta_{2}(\mathrm{Fe})$ hybrid under atmospheric oxygen is not possible. It may be recalled that even the $K_{1}$ value (dissociation constant for the first oxygen bound) of $\alpha_{2}(\mathrm{Ni})-\beta_{2}(\mathrm{Fe})$ hybrid is very low at $\mathrm{pH} 7 \cdot 2 .{ }^{11}$

These series of optical spectra of the hybrid Hbs, $\mathrm{pH}$ dependence of $\alpha_{2}(\mathrm{Ni})-\beta_{2}(\mathrm{Fe}-\mathrm{CO})$ and a comparison of the oxy and carbonmonoxy derivative of $\alpha_{2}(\mathrm{Ni})-\beta_{2}(\mathrm{Fe}-\mathrm{X})$ (where $\mathrm{X}=\mathrm{O}_{2} / \mathrm{CO}$ ) clearly bring out the nature of conformational change and their relation to metal ion environment. This derives substantial support both from sulphhydryl reactivity profile experiments as well as EPR.

\subsection{Sulphhydryl reactivity studies}

Cys $\beta 93$ is located next to the proximal histidine $\beta 92$. As the extent of 5-coordination increases, the proximal histidine nitrogen atom is pulled towards the central metal ion of the porphyrin core, and as a result, more room is created around the $-\mathrm{SH}$ group and hence 4-PDS can easily react with the -SH group and more thiopyridone is evolved, and thus the higher absorption. Therefore, the Cys $\beta$-93 group whose reactivity is used as a structural probe in this study reflects also the coordination aspects. The $-\mathrm{SH}$ reactivity profile seen in figure 3 is in complete accord with the 5-4 coordination ratio profile monitored by optical spectroscopy as noted in series (1). $\mathrm{CuHb}$ which has a lowest ratio of integrated intensity of 5- to 4-coordinated species shows the lowest reactivity and the $\alpha_{2}(\mathrm{FeCO})-\beta_{2}(\mathrm{Cu})$ hybrid, the one with the maximum ratio, shows the highest reactivity. It is interesting to note that the $\alpha_{2}(\mathrm{Fe}-\mathrm{CO})-\beta_{2}(\mathrm{Cu})$ hybrid shows a higher reactivity than $\mathrm{HbCO}$. At this point it is necessary to recall the analysis by Makino and Sugita ${ }^{26}$ on the initial rates of the reaction, which reveal an intermediate, carrying 3 oxygen molecules, that shows a $-\mathrm{SH}$ reactivity even higher than the fully ligated form. In the same way, $\alpha_{2}(\mathrm{Fe}-\mathrm{CO})-\beta_{2}(\mathrm{Cu})$ can be regarded to have a structure which is similar (at the -SH pocket) to the above intermediate with three oxygen molecules. The reason for the $-\mathrm{SH}$ group of $\alpha_{2}(\mathrm{Fe}-\mathrm{CO})-\beta_{2}(\mathrm{Cu})$ being more reactive than that of $\mathrm{HbCO}$ may be attributed to the difference in the ionic radii of the $\mathrm{Fe}^{2+}$ and $\mathrm{Cu}^{2+} \cdot \mathrm{Cu}^{2+}$ being smaller than $\mathrm{Fe}^{2+}$ fits comfortably into the cavity of porphyrin, thereby bringing the nitrogen atom of the proximal histidine towards the porphyrin ring more easily than in the case of normal $\mathrm{Hb}$. This in turn creates larger space in the $-\mathrm{SH}$ pocket resulting in higher reactivity for the hybrid than $\mathrm{HbCO}$. It is interesting to note that though the final reactivity of $\alpha_{2}(\mathrm{Fe}-$ 
$\mathrm{CO})-\beta_{2}(\mathrm{Cu})$ is higher than that of $\mathrm{HbCO}$, the initial reactivity of $\mathrm{HbCO}$ is higher (as shown by the sharper rise in comparison to the other) than that of $\alpha_{2}(\mathrm{Fe}-\mathrm{CO})-\beta_{2}(\mathrm{Cu})$. This may probably be due to the fact that the heme-heme interaction in the tetrameric $\mathrm{HbCO}$ plays a dominant role.

Increasing the $\mathrm{pH}$ increases the extent of $\mathrm{R}$ character of the hybrid, as clearly illustrated in $\alpha_{2}(\mathrm{Ni})$ $\beta_{2}(\mathrm{FeCO}$ ) hybrid $\mathrm{Hb}$ (figure 4$)$. The conformation of the hybrid at pH 6.5 is ' $\mathrm{T}$ ' as evidenced by the Soret band deconvolution which is equally well reflected in the reactivity of the $-\mathrm{SH}$ group of the Cys $\beta 93$. At higher $\mathrm{pH}$, the reactivity increases as the conformation of the tetramer moves to R. It is also known from the optical studies of Shibayama et $a l^{20}$ that the change in the absorption spectra of $\alpha_{2}(\mathrm{Ni})-\beta_{2}(\mathrm{FeCO})$ hybrid $\mathrm{Hb}$ on increase of $\mathrm{pH}$ is due to the increase in the 5-coordination behaviour of $\alpha \mathrm{Ni}$ subunit. This behaviour of the $\alpha$-subunit must be noted in the context of our earlier explanation that the $-\mathrm{SH}$ reactivities of all hybrids are related to the coordination behaviour of the $\beta$-subunit. Now it becomes realistic to say that the $\mathrm{M}-\mathrm{N} \varepsilon \operatorname{His}(\mathrm{F} 8)$ bond in $\alpha$-subunit also has a specific role in modulating the ligand affinity and thereby in triggering the allosteric transition, as was suggested by Fujii et $a l^{27}$. Based on the increase in the reactivity of $-\mathrm{SH}$ group on increasing the $\mathrm{pH}$ of $\alpha_{2}(\mathrm{Ni})-\beta_{2}(\mathrm{FeCO})$ hybrid $\mathrm{Hb}$, it can be concluded that the increase in the 5-coordination behaviour in $\alpha \mathrm{Ni}$ subunit, due to subunit interaction, pushes the $\beta$-Fe subunit to assume stronger 5-coordination behaviour which in effect changes the tertiary structure at the Cys $\beta-93$ residue. The latter causes an increase in the PDS reactivity. It is also supported by the increase in 5- to 4-coordination ratio monitored by optical spectroscopy. In other words, the establishment of $\mathrm{M}-\mathrm{N} \varepsilon$ covalent bond in the $\alpha$-subunit from its dominantly 4-coordinate structure in $\mathrm{T}$ conformation is responsible for $\mathrm{T} \rightarrow \mathrm{R}$ transition. However, the $\mathrm{Fe}-\mathrm{His}$ bond in $\alpha$ and $\beta$-subunits are found to behave differently in different subunits. More support for all these observations and inferences come from EPR results.

\subsection{EPR of R-state hybrid}

The observations by EPR spectroscopy are equally interesting and informative. As has been earlier predicted by Manoharan et al, ${ }^{17}$ the presence of CuPPIX in most tetrameric $\mathrm{Hb}$ gives rise to two different metal ion environments. Species 1 is characterized by higher $g_{\|}$, lower $A_{\|}(\mathrm{Cu})$ and not so well resolved perpendicular component. On the other hand, species 2 is characterized by lower $g_{\|}$, higher $A_{\|}(\mathrm{Cu})$ and a well-resolved perpendicular component due to the hyperfine lines from ${ }^{63,65} \mathrm{Cu}$ and ${ }^{14} \mathrm{~N}$. Hence, species 1 basically is a result of 5-coordination with a ruffled porphyrin ${ }^{28}$ and species 2 is an almost planar 4 coordination $\operatorname{site}^{29}$ (see table 4 ). We have used these basic EPR structure to understand the $\mathrm{Cu}$ containing sites after simulation in hybrid Hbs.

A comparison of $\alpha_{2}(\mathrm{Cu})-\beta_{2}(\mathrm{FeCO})$ and its counterpart $\alpha_{2}(\mathrm{FeCO})-\beta_{2}(\mathrm{Cu})$ hybrid reveal $40: 60$ ratio of species 1 and 2 for the former and $75: 25$ ratio for the latter hybrid. This is in excellent accord with similar trends in the ratio of 5- to 4-coordination from optical spectroscopy (table 2) as well as in the conformational trend measured by $-\mathrm{SH}$ reactivity (figure 3). The presence of both 5- and 4-coordination (species 1 and 2) in $\alpha$-subunit of $\alpha_{2}(\mathrm{Cu}$ )$\beta_{2}(\mathrm{FeCO})$ hybrid indicates the presence of different metal ion environments within the same subunit. On the other hand, the enormous increase in 5-coordination of its counterpart, viz., $\alpha_{2}(\mathrm{FeCO})-\beta_{2}(\mathrm{Cu})$ hybrid is not only because of the inherent presence of $\mathrm{Cu}$ in $\beta$-subunit with strong metal-Ne bond but also because of the push given by the 5 -coordinated $\alpha-\mathrm{Fe}$ subunit. $^{27}$

\subsection{EPR of T-state hybrid and $\mathrm{CuHb}$}

The best fit for $\alpha_{2}(\mathrm{Cu})-\beta_{2}(\mathrm{Ni})$ and its complimentary hybrid $\alpha_{2}(\mathrm{Ni})-\beta_{2}(\mathrm{Cu})$ give the 1 st and 2 nd species ratio as $40: 60$ and $60: 40$ respectively. The presence of species 1 and 2 within the same subunit is indicative of a dynamical process involving 4- and 5-coordination. It is also in accordance with the conformational change by $-\mathrm{SH}$ reactivity profile. Above all, the observation of $1: 1$ combination of species 1 and 2 in the EPR of T-state $\mathrm{CuHb}$ indicates ${ }^{17}$ that this is nothing but a result of dynamics (and hence sum) observed at the individual subunits. It is, therefore, inferred that metal-Ne bond undergoes dynamics both in $\alpha$ and $\beta$-subunits but the 5-coordination is dominant in the $\beta$-subunit as against 4 - in $\alpha$-subunit. Hence, we should not consider the coordination behaviour exclusive to any subunit. The presence of two different metal ion environments within the same subunit was also discussed in the R-structured hybrids alone. There is also a rationale behind the conformational difference between two T-structured metal reconstituted $\mathrm{Hbs}-$ viz., the $\mathrm{T}$ of $\mathrm{CuHb}$ is 
higher than that of $\mathrm{NiHb}$, specially in relation to $\alpha$ subunit. This is due to the relative electronic structural stabilities of 5-coordination environment around the metal with porphyrin in the equatorial plane and Histidine or any such nitrogen base in the 5th coordination. It is very well known that such 5-coordinated nickel (II) complexes are more stable and more in number than the corresponding $\mathrm{Cu}$ (II) systems and hence $\mathrm{CuHb}$ has definitely a tendency to have more of 4-coordination and hence to be more T-structured than $\mathrm{NiHb}$. This relative $\mathrm{T}$ structure is also reflected in their hybrids namely, $\alpha_{2}(\mathrm{Cu})-\beta_{2}(\mathrm{Ni})$ and $\alpha_{2}(\mathrm{Ni})-\beta_{2}(\mathrm{Cu})$ in their optical spectra and $-\mathrm{SH}$ reactivities.

\subsection{Supporting evidence for mixed-metal ion coordination from optical data on $\alpha_{2}(\mathrm{Ni})-\beta_{2}(\mathrm{Cu})$ and $\alpha_{2}(\mathrm{Cu})-\beta_{2}(\mathrm{Ni})$ hybrid $\mathrm{Hbs}$}

Additional evidence for the presence of species 2, namely the 4-coordinated NiPPIX, in both $\alpha_{2}(\mathrm{Ni})$ $\beta_{2}(\mathrm{Cu})$ and $\alpha_{2}(\mathrm{Cu})-\beta_{2}(\mathrm{Ni})$ hybrid Hbs comes from the optical spectra of these two hybrids (figure 10), more clearly so from the Q-band (visible) region. The peak at $558 \mathrm{~nm}$ is assigned to the four coordinate NiPPIX by Shelnutt et al. ${ }^{18}$ Both $\alpha_{2}(\mathrm{Ni})-\beta_{2}(\mathrm{Cu})$ and $\alpha_{2}(\mathrm{Cu})-\beta_{2}(\mathrm{Ni})$ hybrid $\mathrm{Hbs}$ have a peak at $558 \mathrm{~nm}$ indicating the presence of species 2 in both these hybrid Hbs. It is interesting to note that the $558 \mathrm{~nm}$ peak in $\alpha_{2}(\mathrm{Ni})-\beta_{2}(\mathrm{Cu})$ is more intense than it is in its

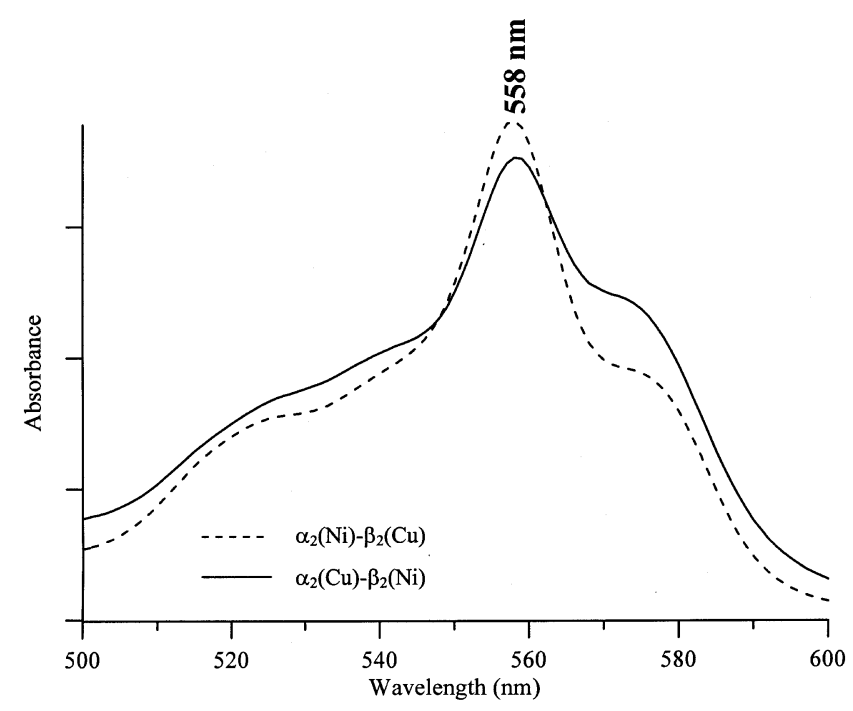

Figure 10. Comparison of Q-band region of the visible spectra of $\alpha_{2}(\mathrm{Cu})-\beta_{2}(\mathrm{Ni})$ and $\alpha_{2}(\mathrm{Ni})-\beta_{2}(\mathrm{Cu})$ hybrid Hbs, both showing peaks at $558 \mathrm{~nm}$. complementary hybrid $\alpha_{2}(\mathrm{Cu})-\beta_{2}(\mathrm{Ni})$. This in turn supports our Q-band EPR spectral simulation results, which shows that $\mathrm{M}^{2+}$ PPIX in the $\alpha$-subunit has $60 \%$ of four coordination behaviour, whereas the $\beta$ subunit has only $40 \%$ of four coordination behaviour. This is clearly reflected in our optical spectra of the two hybrid Hbs. The $\alpha_{2}(\mathrm{Ni})-\beta_{2}(\mathrm{Cu})$ hybrid $\mathrm{Hb}$ with intense $558 \mathrm{~nm}$ peak, has greater amount of 4-coordination behaviour, its complementary hybrid $\alpha_{2}(\mathrm{Cu})-\beta_{2}(\mathrm{Ni})$ hybrid $\mathrm{Hb}$, with less intense $558 \mathrm{~nm}$ peak, has lesser amount of 4-coordination behaviour because of the presence of NiPPIX in the $\beta$-subunit.

Support for the presence of mixed-metal ion coordination in hybrid $\mathrm{Hbs}$ also comes from the recent resonance Raman studies on hybrid Hbs by Swarnalatha et al. ${ }^{30}$ Resonance Raman studies were done on both ' $T$ ' and ' $R$ ' state hybrid Hbs and it was concluded that two different heme environments exist within a similar subunit which is due to the dynamic equilibrium between the 4- and 5-coordination on the hemes with constant "breaking-making" of the $\mathrm{M}-\mathrm{N} \varepsilon$ histidine bond.

A comment on the difference in the optical spectra of $\alpha_{2}(\mathrm{Ni})-\beta_{2}(\mathrm{FeCO})$ and $\alpha_{2}(\mathrm{Ni})-\beta_{2}\left(\mathrm{FeO}_{2}\right)$ hybrids is noteworthy in the light of the work of Fujii et al. ${ }^{27}$ They observed that the first oxygen binding to the $\beta$-heme may be linked to the metal-proximal histidine interaction in the $\alpha$-subunits and the reverse effect is minimal. This may be the reason for the lack of complete oxygenation of the $\beta$-subunit in $\alpha_{2}(\mathrm{Ni})$ $\beta_{2}(\mathrm{Fe})$. Therefore, the oxy derivative should be rigorously called $\left[\left(\alpha^{\mathrm{Ni}} \beta^{\mathrm{Fe}}\right)\left(\alpha^{\mathrm{Ni}} \beta^{\mathrm{FeO}_{2}}\right)\right]$. The proximal histidine interaction with the metal ion in the $\alpha$-subunit, leading to 5 -coordination pushes the $\beta$-heme in such a fashion as to increase the 5- to 4-coordination ratio and hence the conformational push to the $\mathrm{R}$ structure. This is obvious in the case of $\alpha_{2}(\mathrm{Ni})$ $\beta_{2}(\mathrm{FeCO})$ which has a larger 5- to 4-coordination ratio at higher $\mathrm{pH}$ indicating the $\alpha-\mathrm{Ni}$ site has increased amount of $\mathrm{M}-\mathrm{N \varepsilon}$ interaction. The process of formation of this M-His linkage is hence part of a dynamical process within the same subunit, for which we have provided evidence also through EPR.

Support for mixed-metal ion behaviour in $\alpha_{2}(\mathrm{Cu})$ $\beta_{2}(\mathrm{FeCO})$ within the same subunit comes from the earlier results on $\mathrm{Ni}(\mathrm{II})-\mathrm{Fe}$ (II) hybrid $\mathrm{Hbs}$ by Shibayama et $a l^{12}$, who have overlooked the presence of mixed coordination within the $\alpha$ and $\beta$-subunits. In the case of $\alpha_{2}(\mathrm{Ni})-\beta_{2}(\mathrm{FeCO})$, the $\mathrm{N}_{\delta} \mathrm{H}$ signal of the $\alpha(\mathrm{Ni})$ subunits is detected at $77 \mathrm{ppm}$ only at high pHs. At pH 7.4, the $\mathrm{N}_{\delta} \mathrm{H}$ resonance markedly reduces 
in intensity, and at lower $\mathrm{pH}$ or in the presence of IHP, it is difficult to detect. This $\mathrm{N}_{\delta} \mathrm{H}$ resonance occurs as a result of a paramagnetic, 5-coordinated $\mathrm{Ni}(\mathrm{II})$. At high $\mathrm{pH}$, since the hybrid is dominated by the 5-coordinated NiPPIX, the $\mathrm{N}_{\delta} \mathrm{H}$ signal is observed at full intensity. Here it must be noted that even at $\mathrm{pH} 7 \cdot 2$, the observation of $\mathrm{N}_{\delta} \mathrm{H}$ signal due to 5coordinated NiPPIX, is at reduced intensity. This adds support to our Q-band EPR simulation results on $\alpha_{2}(\mathrm{Cu})-\beta_{2}(\mathrm{FeCO})$ hybrid that at neutral $\mathrm{pH}$, CuPPIX in the $\alpha$-subunit exhibits mixed coordination, a 5-coordinated species with axial ligation coming from the Ne-HisF8 and the other without any axial ligation. However, it is necessary to point out that the $\alpha$-subunit always has more 4-coordination with a small amount of 5-coordination character due to mixed-metal ion coordination of proximal histidine prone to motion towards the metal in porphyrin. In other words, the tendency of Ne-His to bond with the metal in the $\alpha$-subunit has the tendency switch "on-off". Since, on an average, M-Ne (His) distance is large, the $\alpha$-subunit heme appears to be 4 -coordinated with the possibility of the said bond getting shorter as $\mathrm{pH}$ increases. It is the other way for the $\beta$ subunit even for ions such as $\mathrm{Ni}(\mathrm{II})$ and $\mathrm{Cu}(\mathrm{II})$ in $\mathrm{M}^{2+}$ PPIX where the tendency is greater towards 5coordination due to generally reduced $\mathrm{M}-\mathrm{N} \varepsilon$ distance. This must also be the reason why we see $1: 1$ of species 1 and 2 distribution in $\mathrm{CuHb} .{ }^{17}$ Exactly for the same reason, species 2 dominates $\alpha_{2}(\mathrm{Cu})$ $\beta_{2}(\mathrm{FeCO}$ ) (which is an intermediate $\mathrm{R}$ conformation) and species 1 dominates $\alpha_{2}(\mathrm{FeCO})-\beta_{2}(\mathrm{Cu})$ hybrid $\mathrm{Hb}$ (which is in an extreme $\mathrm{R}$ conformation).

Support for the mixed-metal ion behaviour in the $\beta$ site of $\alpha_{2}(\mathrm{FeCO})-\beta_{2}(\mathrm{Cu})$, also comes from the earlier results on $\mathrm{Ni}(\mathrm{II})-\mathrm{Fe}(\mathrm{II})$ hybrid Hbs by Shibayama et $a l^{12}$. The proton NMR spectra of deoxy $\alpha_{2}(\mathrm{Fe})$ $\beta_{2}(\mathrm{Ni})$ exhibit a resonance at $70.5 \mathrm{ppm}$ which is assigned to the proximal histidyl $\mathrm{N}_{\delta} \mathrm{H}$ protons. Similar measurements were carried out for the half-liganded $\alpha_{2}(\mathrm{FeCO})-\beta_{2}(\mathrm{Ni})$ and it was found that the CObound $\mathrm{Fe}$ subunits do not show hyperfine-shifted resonances because of diamagnetism of the porphyrin iron. The $\mathrm{N}_{\delta} \mathrm{H}$ resonances of the $\beta(\mathrm{Ni})$ subunits are shifted downfield by approximately 5 ppm upon $\mathrm{CO}$ binding to the partner $\alpha(\mathrm{Fe})$ subunits at $\mathrm{pH} 7.4$ and $\mathrm{pH} 8.5$, but the resonances are somewhat broader than those of the deoxy $\alpha_{2}(\mathrm{Fe})-\beta_{2}(\mathrm{Ni})$. This broadening could have arisen only because of dynamics slightly faster than the NMR timescale involving the NiPPIX relative to $\mathrm{N} \varepsilon-\mathrm{His}$ induced by subunit interaction during the addition of $\mathrm{CO}$ to $\mathrm{Fe}$ subunit. This also adds support to our Q-band EPR simulation results on $\alpha_{2}(\mathrm{FeCO})-\beta_{2}(\mathrm{Cu})$ hybrid that at neutral $\mathrm{pH}$, CuPPIX in the $\beta$-subunit exhibits mixed coordination, a 5-coordinated species with axial ligation coming from the $\mathrm{N} \varepsilon-\mathrm{HisF} 8$ and the other without any axial ligation. Similar effects are also observed in $\alpha_{2}(\mathrm{Ni})-\beta_{2}(\mathrm{Cu})$ hybrid $\mathrm{Hb}$ at $\mathrm{pH}$ 8.5. However, the absence of NMR signal for $\mathrm{N}_{\delta} \mathrm{H}$ resonances of the $\alpha-\mathrm{Ni}$ in the T-structured deoxy $\alpha_{2}(\mathrm{Ni})-\beta_{2}(\mathrm{Fe})$ and also in $\mathrm{NiHb}$ is perplexing! It is, however, possible that $\mathrm{Ni}$ in the $\alpha$-subunit, having only two electrons for providing paramagnetism as compared to 4 in iron, lesser extent of 5-coordination and greater dynamics between 4- and 5-coordination, must have shifted to lower ppm and broadened beyond detection.

\section{Conclusion}

In summary, hybrid Hbs, based on their reactivity towards 4-PDS, have been classified as R-state or Tstate, or R (intermediate) when they show an intermediate reactivity. There exists some correlation between conformational change and coordination behaviour. The same correlation is also observed for hybrids exhibiting the alkaline Bohr effect and for such hybrids having $\mathrm{FeCO}$ or $\mathrm{FeO}_{2}$ as one of the constituents. The Q-band EPR spectral studies on $\mathrm{Cu}(\mathrm{II})$ containing $\mathrm{R}$ - and T-state hybrid $\mathrm{Hbs}$ and subsequent simulation of the resulting spectra reveals the presence of two different metal ion environments for CuPPIX within both the $\alpha$ - and $\beta$-subunits but in varying percentage compositions. All hybrids point to the presence of mixed-metal ion coordination in both subunits and question the acceptance of subunit heterogeneity. In addition, the observation of Fujii and co-workers ${ }^{27}$ that the $\mathrm{M}-\mathrm{N} \varepsilon$ His (F8) bond in the $\alpha$-subunit has also a role in modulating the ligand affinity and thereby triggering the allosteric transition just like the counterpart in $\beta$-subunit, is confirmed by our work. All these are possible only if there is a dynamics of motion between 5- and 4-coordination in all the subunits.

\section{Acknowledgements}

PTM thanks the Department of Science and Technology, Govt. of India for financial support and SR and SV the Council of Scientific and Industrial Research, New Delhi for fellowships. PTM also thanks the Jawaharlal Nehru Centre for Advanced Scientific Research, Bangalore for the Honorary Professorship. 


\section{References}

1. Ackers G K and Smith F T 1987 Annu. Rev. Biophys. Chem. 16583

2. Ogawa S and Shulman R G 1972 J. Mol. Biol. 70 315

3. Ikeda-Saito M, Yamamoto H and Yonetani T $1977 \mathrm{~J}$. Biol. Chem. 2528639

4. Miura S and Ho C 1982 Biochemistry 216280

5. Miura S and Ho C 1984 Biochemistry 232492

6. Perutz M F 1972 Nature (London) 237495

7. Perutz M F, Fersht A R, Simon S R and Roberts G C K 1974 Biochemistry 132174

8. Perutz M F, Kilmartin J V, Nagai K, Szabo A and Simon S R 1976 Biochemistry 15378

9. Inubushi $\mathrm{T}$ and Yonetani $\mathrm{T} 1983$ Biochemistry 22 1894

10. Scott T W, Friedman J M, Ikeda-Saito M and Yonetani T 1983 FEBS Lett. 15868

11. Shibayama N and Morimoto H 1986 J. Mol. Biol. 192331

12. Shibayama $\mathrm{N}$, Inubushi $\mathrm{T}$, Morimoto $\mathrm{H}$ and Yonetani T 1987 Biochemistry 262194

13. Ishimori K and Morishima I 1988 Biochemistry 27 4060

14. Nagai K and Kitagawa T 1980 Proc. Natl. Acad. Sci. (USA) 772033

15. Maxwell J C and Caughey W S 1976 Biochemistry 15388
16. Manoharan P T, Alston K and Rifkind J M 1985 in Biological \& inorganic copper chemistry (eds) K D Karlin and J Zubieta (New York: Adeinine Press)

17. Manoharan P T, Alston K and Rifkind J M $1986 \mathrm{~J}$. Am. Chem. Soc. 1087095

18. Shelnutt J A, Alston K, Ho J-Y, Yu N-T, Yamamoto T and Rifkind J M 1986 Biochemistry 25620

19. Shibayama N, Ikeda-Saito M, Hori H, Itaroku K, Morimoto H and Saigo S 1995 FEBS Lett. 372126

20. Shibayama N, Morimoto H and Miyazaki G $1986 \mathrm{~J}$. Mol. Biol. 192323

21. Kilmartin J V, Fogg J, Luzzana M and RossiBarnerdi L 1973 J. Biol. Chem. 2487039

22. Geraci G, Parkhurst L J and Gibson Q H $1969 \mathrm{~J}$. Biol. Chem. 2444664

23. Rossi-Fanelli A, Antonini E and Caputo A 1958 Biochim. Biophys. Acta 30608

24. Ampulski R S, Ayers V E and Morell S A 1967 Anal. Biochem 32163

25. McLees B D and Caughey W S 1969 Biochemistry 7642

26. Makino N and Sugita Y 1982 J. Biol. Chem. 257163

27. Fujii M, Hori H, Miyazaki G, Morimoto H and Yonetani T 1993 J. Biol. Chem. 26815386

28. Alston K and Storm C B 1979 Biochemistry 794292

29. Manoharan P T and Rogers M T 1969 in ESR of metal complexes (ed.) T F Yen (New York: Plenum Press) p. 143

30. Venkatesh Rao V, Balakrishnan G and Manoharan P T 2002 Biopolymers 67156 